\title{
Collusion in a Differentiated Market and Environmental Network Externality
}

\author{
Pasquale Marcello Falcone ${ }^{1}$ \\ ${ }^{1}$ Department of Law, Philosophy and Economic Studies, Sapienza - University of Rome, Rome, Italy \\ Correspondence: Pasquale Marcello Falcone, Department of Law, Philosophy and Economic Studies, Sapienza - \\ University of Rome, Piazzale Aldo Moro, 5, 00185, Rome, Italy. E-mail: pasquale.falcone@uniroma1.it
}

Received: June 23, 2014 Accepted: July 23, 2014 Online Published: August 25, 2014

doi:10.5539/res.v6n3p102 URL: http://dx.doi.org/10.5539/res.v6n3p102

\begin{abstract}
We analyse the effect of a "green network externality" in a context of consumers' environmental sensitiveness and competition between firms in both environmental quality and product prices. In particular, we investigate firms 'aptitude to implicitly collude on prices in a vertically differentiate market. We find that green network effects hamper collusion. We also find that firms collude if they recognize an adequate value in future joint profits.
\end{abstract}

Keywords: collusion, consumer behavior, environmental externality

\section{Introduction}

Eco-friendly products represent an increasingly share of household expenditure. According to the recent surveys by the European Commission $(2008,2009), 83 \%$ of Europeans citizens particularly care about the impact of products on the environment when buying; $75 \%$ are "ready to buy environmentally friendly products even if they cost a little bit more", compared to $31 \%$ in 2005 . However, in 2008 , only $17 \%$ have recently bought "products marked with an environmental label". (Brécard, 2009)

Several consumer surveys show a further peculiarity of eco-friendly products: the majority of consumers perceive them as having a greater (environmental) quality than the standard ones. Indeed, European Commission (2005) and OECD (2002) studies highlight that if they were sold at the same price as their more polluting counterparts, most of consumers would turn towards green products experiencing a grater pleasure of consuming them as the number of consumers doing the same.

The uniqueness of our model principally derives from the assumption of a network effect in a green market on price and quality strategy of firms. In particular, we looks at network firms' incentive to set environmental compatibility (i.e. through compliance with an environmental standard) under a tacit collusive agreement. It has been shown that firms can benefit from network externalities (Economides, 1996) since product becomes more valuable to consumers as more consumers choose the same product. However, despite the benefits of the positive externalities just noted, network externalities also can have an adverse effect on firms by hampering their capacity to implicitly collude (Shy, 2001).

The present article looks at this issue. In particular, we investigate firms' ability to tacitly collude on prices in markets for green products in infinitely repeated duopoly game of vertical and horizontal product differentiation. A scenario in which firms can collude in markets for vertically differentiated products has been studied by Chang (1991). He sets up a model à la Hotelling where production costs are expected to be zero and firms play trigger strategies as in Friedman (1971). His major conclusion is that firms find more arduous to collude when the products are less differentiated. Furthermore, Hackner (1996) has found that Chang's findings support changes in the different punishment strategies for deviating from collusion. Our study diverges from these two contributions since it takes into account a green market and aims at providing insight for environmental policies. To our knowledge no previous analysis has been carried out on the firms' ability to tacitly collude on prices in green markets with network effects.

The paper proceeds as follows. Section 2 sets up the model. Section 3 derives the static equilibriums and Section 4 analyses the equilibrium in the super-game that we take into account. Section 5 concludes. 


\section{Model}

First of all, it is assumed that the environmental characteristics of a good do not influence the other characteristics of the good. Moreover, as is stressed by Brécard (2011), an environmentally friendly product is perceived as of higher quality than the standard product by consumers and is consequently more costly. Against this background, a number of consumer surveys show this feature of green products: most consumers perceive them as having a higher (environmental) quality than their competitors. Indeed, European Commission $(2008,2005)$ and the OECD (2002) studies highlight that if they were sold at the same price as their more polluting counterparts, a large majority of consumers would turn immediately towards green products, given their environmental sensitiveness. Therefore, a further important aspect of this model comes from the assumption of the presence of green consumers that patronise the good they choose to buy (i.e., they specifically care about the environmental impact of goods they buy).

The basic setup follows Hotelling (1929). There are two single - product firms $(1,2)$ which produce a good that can be vertically differentiated in environmental quality. Firm 1 is located at 0 on the linear city of unitary length; firm 2 is located at 1 . They offer products of environmental quality $v_{i}=(H, L)$ and compete in price $p_{i}, i \in\{1,2\}$. Each consumer buys at most one unit of the product.

By referring to the analysis proposed by Economides and Himmelberg (1995), it is possible to specify the general utility function that characterizes a single individual $U(v, s e)$ by assuming that it is separable in the following way:

$$
\mathrm{U}(\mathrm{v}, \mathrm{se})=v+\alpha(\mathrm{se})-t
$$

where $t$ indicates the transportation cost of consumer from his ideal point of environmental quality (with $t>0$ ) and $\alpha(s e)$ represents the value of the green network externality that is a function of the consumer's expectations on the future size of the green network. It is further assumed that $v$ is uniformly distributed over the interval $[0,1]$. Let us assume that $\alpha^{\prime}>0$ and $\alpha^{\prime \prime}<0$ : that is, the effect of the network externality on the individual utility increases with the expected size of the network at a decreasing rate. This assumption has a natural interpretation. Contrast the effects of entry of a new green consumer when the network is very small or quite large. In the former case, the relative increase in the network size is substantial; therefore, the benefit in term of greater externalities is likely to be larger than in the case of entry in a large-size network. Finally, it is natural to assume that a network with null expected size $\alpha(0)$ does not generate any externality. If $p$ is the price for accessing the green network, then for a given expectation level se it is possible to identify the so-called marginal consumer, that is the one who obtains exactly the same utility by buying or not buying the green good. The marginal consumer is characterized by a basic evaluation $v^{\wedge}$ such that the net utility in case of purchase turns out to be null. Formally:

$$
v+\alpha(\mathrm{se})-\mathrm{p}-\mathrm{t}=0
$$

from which we get:

$$
v^{\wedge}=p-\alpha(\text { se })
$$

Given the price and the expectations about the green network size, consumers who have a basic evaluation $v \geq v^{\wedge}$ join the network by buying the green good and get a positive utility, those with $v<v^{\wedge}$ stay out. A consumer located at point $x \in[0,1]$ who buys from firm $i$ receives the following utility:

$$
U_{i} \begin{cases}v_{i}-t * x+\alpha * n_{i}-p_{i} & \text { if } i=1 \\ v_{i}-t *(1-x)+\alpha * n_{i}-p_{i} & \text { if } i=2\end{cases}
$$

The products are vertically differentiated because of the potentially different environmental quality levels that are determined at the first stage of the game. To avoid uninteresting case distinctions we assume throughout that all consumers $x \in[0,1]$, as in the models of vertical product differentiation developed by Mussa and Rosen (1978) and Cremer and Thisse (1999), obtains utility from the consumption of the first unit of the good and purcheses one unit of the good or at all. Each firm select one variant of a product to produce and chooses its price. Thus, the demands faced by firms are:

$$
D_{1}\left(p_{1}, p_{2}\right)=\widehat{x} \text { and } D_{2}\left(p_{1}, p_{2}\right)=1-\widehat{x}
$$

Finally, we assume that firms produce with constant and identical marginal costs that are normalized to 0 . Therefore, the firms' profits are:

$$
\pi_{1}\left(p_{1}, p_{2}\right)=p_{1} \widehat{x} \text { and } \pi_{2}\left(p_{1}, p_{2}\right)=p_{2}(1-\widehat{x})
$$


In order to have firms earning positive profits we assume that the green network externality is bounded, $\alpha \in\left(0, \frac{1}{2}\right)$. As in Shy and Thisse (1999), we still suppose that $v>\frac{3}{2}$, which means that environmental sensitive consumers always find optimal to buy a green product.

Following Friedman (1971), we examine an infinitely repeated game in which actors play trigger strategies. In particular, firms start by practicing collusive price and keep on charging such price until one of them deviates. If it happens then both firms revert to the Nash equilibrium in the following stages. Moreover, following Martinez-Sanchez (2012), we assume full information such that if a firm has deviated it is instantaneously perceived but the punishment is executed in the subsequent stage.

We try to obtain the sub-game perfect equilibrium (SPE) of the infinitely repeated game. Hence, firms tacitly collude on price, as a SPE, if and only if the current value of collusion profits, given the presence of an environmental standard to comply with, goes beyond the deviation profit summed to the current value of the firm punishment. Namely, collusion appears when:

$$
\sum_{t=0}^{\infty} \delta \pi_{i}^{C} \geq \pi_{i}^{D}+\sum_{t=1}^{\infty} \delta \pi_{i}^{N} \forall \mathrm{i}=1,2
$$

in which $\delta$ identifies the discount factor and $\pi_{i}^{C}, \pi_{i}^{D}$ and $\pi_{i}^{N}$ are the one stage collusion, deviation and Nash profits of firm $i=1,2$ respectively.

The time structure of the game is as follows:

- At stage 1, the two firms decide whether or not to produce with a higher environmental quality (i.e. to comply or not to an environmental standard).

- At stage 2, firms choose their prices $p_{i}, i \in\{1,2\}$, simultaneously, consumers decide from which firm to buy, and payoffs are realized.

- From stage 3 to $n \rightarrow \infty$, firms play trigger strategies.

\begin{tabular}{|c|c|c|c|} 
Stage 1 & Stage 2 & Stage 3 & Stage $n$ \\
\hline Choosing & $\begin{array}{c}\text { Price competition, } \\
\text { Consumers buy, } \\
\text { Payoffs are made }\end{array}$ & Trigger strategies \\
\hline
\end{tabular}

Figure 1. Time structure of the model

In the following part, we seek to derive the one stage Nash equilibrium in a vertically differentiated duopoly and the firms' best deviation strategies from the collusive compliance taking into account green network effects.

\section{Equilibrium}

In order to find the punishment strategies and related profits, which are the Nash profits, equivalent to the duopoly equilibrium we follow Shy and Thisse. They emphasized that, in a duopoly context, there exists a symmetric equilibrium in which both firms charge price $p^{N}$ and achive the profit $\pi^{N}$, where

$$
p^{N}=\frac{1-2 \alpha}{1-\alpha} \text { and } \pi^{N}=\frac{1-2 \alpha}{2(1-\alpha)}
$$

When firms decide to (tacitly) collude on prices, they essentially act as a monopolist sharing the market equivalently and leaving the last consumer to be served without any utility. Therefore, given that firms, 1 and 2, are symmetrical and are situated at the edges of the interval $[0,1]$, they reach highest profits by increasing prices up to the point where consumer with preferences $x=\frac{1}{2}$ is indifferent between purchasing or not the green product, so they charge price $p^{C}=v-\alpha n_{i}^{C}-\frac{1}{2}$. Note that setting a lower price would not increase demand and setting a higher price would make some consumers decide not to purchase. Therefore, we arrive at the following preposition: 
Preposition 1 When both firms tacitly collude on prices in vertically differentiated duopoly and green network externalities, the price they set and the payoff they obtain are:

$p^{C}=v-\frac{1-2 \alpha}{2(1-\alpha)}$ and $\pi^{C}=\frac{p^{C}}{2}=\frac{v}{2}-\frac{1-2 \alpha}{4(1-\alpha)}$

Proof: see Appendix.

Considering that $\alpha \in\left(0, \frac{1}{2}\right)$ and $v>\frac{3}{2}$, we have that $p^{C}>p^{N}$, that results to be contradictory to the result found by Belleflamme and Picard (2007) as already shown by Martinez-Sanchez (2012). This is because they do not contemplate increasing returns for firms due to consumers' higher willingness to pay given the green network effect.

Generally, a firm choose to cheat by deviating from previous collusive agreement if it is advantageous. In this situation, it could charge a slightly lower price and takes a portion of the market if competitor's price is low enough or even seize the entire market if counterpart's price is high enough. If a firm chooses to capture the entire market, it charges a price that brings the consumer that most dislikes the low environmental quality product indifferent between both quality products. Thus, the ideal deviation price results to be:

$$
p^{D}(p)= \begin{cases}\frac{p}{2}+\frac{1-2 \alpha}{2(1-\alpha)} \text { if } p \leq \frac{3(1-2 \alpha)}{(1-\alpha)} \\ p-\frac{1-2 \alpha}{(1-\alpha)} \text { if } p>\frac{3(1-2 \alpha)}{(1-\alpha)}\end{cases}
$$

Considering that the $p^{C}=k-\alpha n_{i}^{C}-\frac{1}{2}$, the ideal deviation price and profit are:

$$
\begin{gathered}
p^{D}=\left\{\begin{array}{c}
\frac{v}{2}+\frac{1-2 \alpha}{4(1-\alpha)} \text { if } v \leq \frac{7(1-2 \alpha)}{2(1-\alpha)} \\
v-\frac{3(1-2 \alpha)}{2(1-\alpha)} \text { if } v>\frac{7(1-2 \alpha)}{2(1-\alpha)}
\end{array}\right. \\
\pi^{D}=\left\{\begin{array}{c}
\left(\frac{v}{2}+\frac{1-2 \alpha}{4(1-\alpha)}\right)+\left(\frac{1}{8}+\frac{v(1-\alpha)}{4(1-2 \alpha)}\right) \text { if } v \leq \frac{7(1-2 \alpha)}{2(1-\alpha)} \\
v-\frac{3(1-2 \alpha)}{2(1-\alpha)} \text { if } v>\frac{7(1-2 \alpha)}{2(1-\alpha)}
\end{array}\right.
\end{gathered}
$$

As it is possible to note the deviating firm takes the entire market if $v$ is high enough $v>\frac{7(1-2 \alpha)}{2(1-\alpha)}$; otherwise it obtains just a portion of the green market (Martinez-Sanchez, 2012).

\section{Analysis}

As it is possible to notice in Preposition 2 the deviating firm decides to cheat if and only if his discount factor is adequately low.

Preposition 2 Collusive agreement is tenable as a sub game perfect equilibrium (SPE) if and only if

$$
\delta \geq \underline{\delta}=\frac{\pi^{D}-\pi^{C}}{\pi^{D}-\pi^{N}}=\left\{\begin{array}{c}
\left(\frac{v}{2}+\frac{1-2 \alpha}{4(1-\alpha)}\right)+\left(\frac{1}{8}+\frac{v(1-\alpha)}{4(1-2 \alpha)}\right) \text { if } v \leq \frac{7(1-2 \alpha)}{2(1-\alpha)} \\
v-\frac{3(1-2 \alpha)}{2(1-\alpha)} \text { if } v>\frac{7(1-2 \alpha)}{2(1-\alpha)}
\end{array}\right.
$$

where $\underline{\delta}$ identifies the lowest discount factor serving to hold up collusive agreement between firms.

From Preposition 3 we find that a greater green network effect hampers collusion because it implies a bigger impact on cheating firm profits. Particularly, a greater consumer environmental sensitiveness make the network externality implying a higher deviation profit because the deviation price increases and the cheating firm obtains a larger portion of the market or even the entire green market.

Proposition 3 The lowest discount factor serving to hold up collusive agreement is rising on $\alpha$. 


$$
\frac{\partial \delta}{\partial \alpha}=\left\{\begin{array}{l}
\frac{16 v}{\left(5+2 k-2 \alpha(5+\mathrm{k})^{2}\right.}>0 \text { if } v \leq \frac{7(1-2 \alpha)}{2(1-\alpha)} \\
\frac{v}{4(4 \alpha+v(1-\alpha)-2)^{2}}>0 \text { if } v>\frac{7(1-2 \alpha)}{2(1-\alpha)}
\end{array}\right.
$$

We found that the lowest discount factor able to guarantee collusion is directly dependent on $v$ (consumer' utility for consuming his ideal product) when $\alpha=0$ for a positive value of $v$. However, in the limit case in which $\alpha=\frac{1}{2}$, it is not dependent of $v$ in that $\lim _{\alpha \rightarrow \frac{1}{2}} \frac{\delta}{2}=\frac{1}{2}$. Accordingly, we might conclude asserting that both firms collude even if the green network effect turn out to be very important.

\section{Conclusions}

The analysis of the effect that the number of consumers of an eco-friendly product has on their utility on consuming such product provided new insights about the working of a green market.

In this article we investigate firms' aptitude to collude and the effects of network externality on that capacity. The theoretical background taken into account is an infinitely repeated duopoly game of vertical product differentiation in which actors play grimmer strategies.

In accordance with our model firms implicitly collude if and only if they worth forthcoming profits adequately, and a greater relevance of the green network effects hampers collusion. These findings suggest that policy makers should give particular consideration to the evolution of markets for eco-friendly products to avoid tacit agreement between firms in producing low quality (standard) product. However, the green network externality cannot however alone offset for the effects of pollution and imperfect competition on welfare. The setting up of an adeguate taxation system would allow the achievement of the equilibrium to the eco-friendly optimum. Against this background, as already shown by Brécard (2009), the ideal strategy would consist in setting a pigouvian tax and a subsidy for the green purchase able to convert or dismis the low quality product firm from the market.

\section{References}

Belleflamme, P., \& Picard, P. M. (2007). Piracy and Competition. Journal of Economic and Management Strategic, 16, 351-383. http://dx.doi.org/10.1111/j.1530-9134.2007.00142.x

Brécard, D. (2009). Environmental policy in a differentiated market with a green network effect. Working Paper. Retrieved from https://hal.inria.fr/file/index/docid/442460/filename/LEMNA_WP_200943.pdf

Brécard, D. (2011). Environmental tax in a green market. Environmental \& Resource Economics, 49(3), $387-403$. http://dx.doi.org/10.1007/s10640-010-9438-6

Chang, M. -H. (1991). The Effect of Product Differentiation on Collusive Pricing. International Journal of Industrial Organization, 9, 453-469. http://dx.doi.org/10.1016/0167-7187(91)90023-E

Cremer H., \& Thisse J. F. (1999). On the Taxation of Polluting Products in a Differentiated Industry. European Economic Review, 43, 575-594. http://dx.doi.org/10.1016/S0014-2921(98)00021-X

Economides, N. (1996). The economics of networks. International Journal of Industrial Organization, 14(6), 673-699. http://dx.doi.org/10.1016/0167-7187(96)01015-6

European Commission. (2005- 2008). Attitudes of Europeans citizens towards the environment. Eurobarometer (pp. 217-295).

Friedman, J. (1971). A non cooperative equilibrium for supergames. The Review of Economic Studies, 38(1), 1-12. http://dx.doi.org/10.2307/2296617

Häckner, J. (1996). Optimal Symmetric Punishments in a Bertrand Differentiated Products Duopoly. International Journal of Organization, 14, 611-630. http://dx.doi.org/10.1016/0167-7187(95)00509-9

Martínez-Sánchez, F. (2012). Collusion in Software Market. Economics Bulletin, 32(2), 1345-1352. Retrieved from http:/www.accessecon.com/Pubs/EB/2012/Volume32/EB-12-V32-I2-P128.pdf

Mussa, M., \&Rosen, S. (1978). Monopoly and Product Quality. Journal of Economic Theory, 18, $301-317$. http://dx.doi.org/10.1016/0022-0531(78)90085-6

OCDE. (2002). Report of the OECD workshop on information and consumer decision making for sustainable consumption, Working Party on National Environmental Policy, ENV/EPOC/WPNEP(2001)16/FINAL. 
Shy, O. (2011). A Short Survey of Network Economics. Review of Industrial Organization, 38, 119-149. http://dx.doi.org/10.1007/s11151-011-9288-6

\section{Appendix A}

\section{Proof of Preposition 1}

Following the Martinez-Sanchez (2012) approach, we make the assumption that the market is fully covered, so that firms set price in such a way that the consumer who is indifferent between buying high value product (i.e. compliant with an environmental standard) and low quality product, does not obtain utility if he buys any products. Given that, $p_{1}=v+\alpha n_{1}-\hat{x}$ and $p_{2}=v+\alpha n_{2}-(1-\hat{x})$ we find that:

$$
n_{1}=\frac{\hat{x}}{1-\alpha} ; n_{2}=\frac{1-\hat{x}}{1-\alpha} ; p_{1}=v-\frac{(1-2 \alpha) \hat{x}}{(1-\alpha)} ; p_{2}=v-\frac{(1-2 \alpha)(1-\hat{x})}{(1-\alpha)}
$$

The firms' profit and the FOC are given by:

$$
\begin{gathered}
\max _{\{\hat{x}\}} \pi(\hat{x})=p_{1} \widehat{x}+p_{2}(1-\widehat{x})=\left(v-\frac{(1-2 \alpha) \hat{x}}{(1-\alpha)}\right) \hat{x}+\left(v-\frac{(1-2 \alpha)(1-\hat{x})}{(1-\alpha)}\right)(1-\hat{x}) \\
\frac{\partial \pi(\widehat{x})}{\partial \hat{x}}=\frac{2(1-2 \alpha)(1-2 \widehat{x})}{1-\alpha}=0
\end{gathered}
$$

From the FOC we know that $\widehat{x}^{*}=\frac{1}{2}$ maximizes the joint profit. Therefore, the equilibrium prices are:

$$
p^{*}=p_{1}^{*}=p_{2}^{*}=v-\frac{1-2 \alpha}{2(1-\alpha)}
$$

We will show now that our assumption of the market being full covered was exact. If the prices are greater than $p^{*}$, then the market will be incompletely covered since those consumers located around the interval $[0,1]$ does not buy any good. Considering that $n_{1}=\frac{\hat{x} 1}{1-\alpha}$ and $n_{2}=\frac{1-\hat{x} 2}{1-\alpha}$, the firm $i=1,2$ charges the price in such a way that the consumer who is indifferent between purchasing or not does not attain any utility if he purchases. Therefore:

$$
v+\alpha n_{1}-\hat{x} 1-p_{1}=0 \text { and } v+\alpha n_{2}-(1-\hat{x} 2)-p_{2}=0
$$

From which we find that the number of buyers from each firm is:

$$
\hat{x}_{1}=\frac{1-\alpha}{1-2 \alpha}\left(v-p_{1}\right) ; 1-\hat{x}_{2}=\frac{1-\alpha}{1-2 \alpha}\left(v-p_{2}\right)
$$

When the market is not fully covered, the firms' profit function and the FOC are:

$$
\begin{gathered}
\max _{\left\{p_{1,}, p_{2}\right\}} \pi\left(p_{1,} p_{2}\right)=p_{1} \widehat{x} 1+p_{2}(1-\widehat{x} 2)=\left[p_{1}\left(v-p_{1}\right)+p_{2}\left(v-p_{2}\right)\right] \frac{1-\alpha}{1-2 \alpha} \\
\frac{\partial \pi\left(p_{1}^{*} p_{2}^{*}\right)}{\partial p_{i}}=\left(v-2 p_{i}\right) \frac{1-\alpha}{1-2 \alpha} i=1,2
\end{gathered}
$$

Given we conjecture that $v>\frac{3}{2}$, we have that: 


$$
\frac{\partial \pi\left(p_{1}^{*} p_{2}^{*}\right)}{\partial p_{i}}=\left(\frac{1-2 \alpha}{1-\alpha}-v\right) \frac{1-\alpha}{1-2 \alpha}<0 i=1,2
$$

Consequently, firms have no reason to increase the price upon $p^{*}$, and the market is completely covered. Since $\widehat{x}^{*}=\frac{1}{2}$, we obtain that $\pi^{*}=\frac{p^{*}}{2}$.

\section{Copyrights}

Copyright for this article is retained by the author(s), with first publication rights granted to the journal.

This is an open-access article distributed under the terms and conditions of the Creative Commons Attribution license (http://creativecommons.org/licenses/by/3.0/). 